\title{
The Status Quo, Problems and Research Countermeasures of Teaching Chinese at Primary Schools in Thailand
}

\author{
Qin Ling \\ Xi'an University, Shaanxi Xi'an,710065
}

Keywords: Thailand; Primary School Students; Teaching Chinese

\begin{abstract}
In Thailand, with the in-depth and extensive implementation of teaching Chinese, an increasing number of elementary schools are offering Chinese course. This paper analyzes the Chinese learning characteristics of primary school students in Thailand, a special Chinese-learning group, the current status of teaching and problems in the syllabus and textbooks. And in view of the existing problems, this paper discusses countermeasures for teaching Chinese in a bid to provide certain reference for the in-depth implementation of teaching Chinese at primary schools in Bangkok and even in the entire Thailand.
\end{abstract}

\section{The Development of Teaching Chinese in Thailand}

In recent years, with the improvement of China's comprehensive strength and the frequent exchanges between China and Thailand, the Thai government has gradually relaxed its Chinese education policy. The Thai Education Committee has incorporated Chinese language into the national education system. In 2016, it promulgated the "Strategic Plan to Promote Chinese Teaching and Enhance National Competitiveness". In 2011, according to the incomplete statistics of the Ministry of Education of Thailand, the number of primary and secondary schools offering Chinese courses had reached 1,200. In 2012, Xu Lin, Director of Office of Chinese Language Council International, said at the joint meeting of the Confucius Institutes in Asia and Oceania: "At present, the number of students learning Chinese in Thailand has increased from 80,000 in 2003 to 800,000, and nearly 3,000 schools have Chinese courses." Today, in Bangkok, the capital of Thailand, Chinese language courses have been set at all elementary schools, and more and more schools in other provinces have set Chinese courses. In addition, the Royal Thai Education Station has also launched Chinese TV teaching to benefit millions of primary school students across Thailand.

\section{Status Quo of Teaching Chinese at Primary Schools in Thailand}

Thailand was the first Asian country to incorporate Chinese into the national education system. Therefore, although the "Chinese fever" started late in Thailand, it has developed rapidly. Particularly, the teaching of Chinese language at primary school is a new force that has risen suddenly and spread across Thailand, but behind the blossom phenomenon, various problems have become gradually apparent, gradually attracting people's attention.

\section{Students' Learning Characteristics}

\section{(1) Learning Purpose is Weak with a Lack of Initiative}

Compared with adults, primary school students are immature in their mental development and fail to establish a sound outlook on life and self-values. Their motives for learning Chinese are vague, their purpose is unclear, and they lack the lasting interest in and learning strategies for learning Chinese. They mostly learn Chinese passively: First, because the school has opened a Chinese class, there is no choice; Second, China-Thailand trade and cultural ties are increasingly close. Learning Chinese well can lead to better personal development in the future. Therefore, they are required by parents to learn Chinese. These reasons lead to their lack of conscious initiative in learning, and their enthusiasm for learning is not high. 


\section{(2) They have Poor Self-control Ability and Low Learning Efficiency.}

Thailand is a Hinayana country. The people are bleak and tolerant, and the pace of doing things is slow. Thai schoolchildren also have this cultural identity. Since 2004, Thailand has implemented 15 years of compulsory education throughout the country. Because students do not have the pressure to go to school, and the concept of "happy education" is pursued in Thailand, the concept of time for primary school students is weak, the attitude of learning is sloppy, there is no strong discipline concept, and their restraint ability at classroom is poor. During the class, the students squatted under the table, sat on the ground, and walked around the classroom at random. The phenomenon of free access to the classroom on the grounds of drinking water and going to the toilet was commonplace. In addition, Chinese classes are not compulsory, and Chinese language grades are not used as a basis for further studies. Therefore, primary school students in the Chinese class generally appear as: willing to learn Chinese knowledge, but do not pay attention to Chinese skills training; willing to participate in classroom activities but are not willing to preview and review.

(3) They have a Weak sense of Competition and a Strong Ability to Cooperate.

The formation of psychology and personality traits of Thai primary school students is closely related to the tropical climate of Thailand and the influence of thousands of years of Buddhist culture. The temperament of the students has made them less competitive and have no strong sense of competition in their studies. In school, test scores are not the only criterion for assessing the excellence of students. Therefore, in the process of learning, students and parents never have to score, and they will not have to study hard and get to the top place. In 1911, Rama VI introduced the Boy Scout system into Thailand as a compulsory subject for the school. In addition to training students' field survival ability and survival skills, it also aims to cultivate students' team spirit and cooperation awareness. Therefore, it is the same in learning. Students are more willing to participate in group-based learning activity competitions and show a strong spirit of cooperation in the fight for group honors.

\section{Teachers' Teaching}

Due to the rapid development of Chinese language teaching throughout Thailand, the number of teachers is seriously insufficient, which leads to the low entry threshold for Chinese teachers and the lack of professionalism of the teaching staff. At present, there are mainly the following sources of teaching for Chinese teaching: First, the volunteers sent by Office of Chinese Language Council International have a bachelor's degree or a master's degree. Most of them have a background in Chinese international education. Second, the number of undergraduate graduates with formal Chinese education in Thailand is relatively small. Third, Chinese teachers whose native language is Chinese (Chinese) do not have a background in Chinese and education, and they are highly mobile. Fourth, Thai-Chinese teachers have problems with low academic qualifications. It can be seen that the current serious shortage of Chinese language teachers in primary schools in Thailand and the uneven quality of Chinese teachers are the main factors restricting the development of Chinese teaching.

Although Chinese expatriate teachers have a professional background, and Office of Chinese Language Council International also organizes training before they travel, most of these teachers have no teaching experience or lack of teaching experience. They often try to bring Chinese teaching management methods into the Thai classroom, unconsciously carry out the Chinese-style classroom teaching mode in teaching and increase the after-school assignments. Student's academic performance. But in reality, due to language barriers, many teachers' classroom instructions can't meet the maneuvering needs of classroom management. The professional knowledge system of Thai teachers is imperfect and lacks the basic theories and basic knowledge of Chinese and linguistics. They do not systematically study Chinese phonetics, Chinese characters, vocabulary, and grammar. They often follow the book, have less knowledge, less oral communication, and make more knowledge errors. In short, at present, Chinese primary school Chinese teachers cannot easily control the classroom or have weak professional knowledge. They lack the theory of second 
language teaching and cannot use the best teaching methods to carry out classroom teaching.

\section{Syllabus and Textbooks}

Thailand is the first Asian country to incorporate Chinese into the national education system, and Chinese education is booming in Thailand. However, the Ministry of Education of Thailand has not compiled a Chinese language syllabus that guides the overall situation for many years, nor does it clearly stipulate the level of students' Chinese reading at each stage. Therefore, at the primary schools in Thailand, the starting grades for learning Chinese, the number of hours of Chinese classes per semester, the progress of teaching, and the selection of teaching materials are all decided by the school. In some primary schools with regular classes and key classes, the choice of textbooks, the arrangement of class time, the number of semester sessions of Chinese cultural activities, and the arrangement of teachers are also different.

The teaching materials are the materials for teachers' teaching and student learning. The teaching activities should be carried out around the teaching materials. However, due to the lack of a unified syllabus, the construction of Chinese primary school textbooks in Thailand is relatively lagging. So far, there are no Chinese textbooks that are popular throughout the country. The mixed use of textbooks undermines the overall systemic nature of the textbooks. Many students cannot obtain continuous development of Chinese knowledge after transfer or upgrade. After reviewing the use of textbooks in primary schools in Bangkok and the prefectures, you will find a wide variety of textbooks. Take the reader service department of Thailand Chulalonggong Publishing House as an example, there are more than 40 kinds of Chinese textbooks for children in the service department. However, many of these children's textbooks have only been published once and have not been republished.

At present, the textbooks circulating in primary schools include Chinese textbooks, local textbooks, and Hong Kong and Taiwan. These textbooks are sometimes in traditional complex Chinese and sometimes in simplified Chinese, and the content also has some regional characteristics. Most of the textbooks are not written according to the theory of second language acquisition, nor do they consider the level of psychological cognition of primary school students. Therefore, the quality materials that are really suitable for primary school students are very scarce. Although the textbook "Experience Chinese" (Primary School Edition) promoted by Office of Chinese Language Council International is in line with the concept of foreign language textbooks, it is far from meeting the needs of Thai primary and secondary school students to learn Chinese. The lack of unity and applicability of primary school Chinese textbooks is an urgent problem in Chinese language education in Thailand.

\section{Countermeasures}

\section{Position Teaching from the Characteristics of Primary School Students}

Thai primary school students are lively and have a short duration of attention. Students with different family backgrounds have different learning objectives and learning habits. Primary school language teaching should follow the principle of "taking students as the main body", "taking interest as the leading factor" and "communication as the center". It is necessary to cultivate students' interest in Chinese according to their psychological characteristics, needs and preferences, and to cultivate pure speech and good sense of language as the focus of learning.

While ensuring the teaching objectives, we will actively explore and try the teaching methods that are suitable for the characteristics of primary schools in Thailand. In response to the slow-paced learning style of students, the difficulty of controlling the content of the course and the rhythm of the teaching, pay attention to the proportion of time for review, teaching and training, and promote the memory of students in the classroom. Through the use of modern teaching methods such as sound, picture, sound and other means of knowledge dissemination, enrich the teaching content, carry out various Chinese activities to cultivate students' enthusiasm for creation, and promote their understanding of Chinese culture and improve their communicative competence in Chinese. 
In short, teachers should follow the local customs, face students and classrooms with an open and inclusive attitude, control the teaching content and teaching progress, encourage students' enthusiasm in an encouraging way, and change students' learning attitudes in a relaxed and humorous learning atmosphere. Teachers can use the group competition to mobilize students' classroom participation.

2. Improve Teachers' Skills through Cooperation

To ensure a high level of education quality, it is necessary to ensure that there are a sufficient number of teachers with reasonable structure and quality standards. With the expansion of the source of Chinese learners of Thai primary school students, the requirements for teaching quality are getting higher and higher. When Office of Chinese Language Council International is sending volunteers, the training of teachers' skills should be refined. Relevant departments and schools in Thailand should gradually raise the entry threshold for Chinese teachers and implement Chinese teachers to hold certificates. For example, the Chinese Teacher Certification, Chinese Education Bachelor's degree or HSK Chinese Proficiency Certificate of the Ministry of Education of Thailand can be used as the basis for appointment. Because the opportunities for Thai teachers to speak Chinese are limited to the classroom, the lack of a good language environment for learning Chinese hinders their improvement of Chinese knowledge. The Confucius Institutes in Thailand, the Confucius Classroom and the Hankook ASEAN Center should assist the Ministry of Education in Thailand in organizing a variety of courses for teachers to improve their educational level and teaching level. In the past ten years, the Chinese Ministry of Education has been providing scholarships for overseas students or undertaking part of training fees for Thai teachers in China, in accordance with the agreement between the two countries; Each year, 200-500 volunteers are sent to teach in Thailand, and participate in research and development of standardized Chinese textbooks suitable for use in primary and secondary schools in Thailand. This cooperation initiative has provided support for the development of Chinese language teaching in Thailand in terms of teacher resources and textbook compilation, and the quality of education has been guaranteed to a certain extent. The primary schools in Thailand should also establish an assessment system for Chinese teachers to ensure the quality of Chinese teaching in the school by means of public teaching and student evaluation.

3. Pay Attention to the Continuity and Systematicness of Chinese Education

The syllabus is the main basis for the preparation of textbooks and teachers for teaching. It is also an important indicator for examining and assessing students' academic performance and measuring the quality of teachers' teaching. It is imperative that the Ministry of Education of Thailand should launch a unified Chinese language teaching syllabus as soon as possible, formulate a Chinese language proficiency test system for primary school students, and comprehensively guide Chinese language teaching in primary schools.

The textbook reflects the purpose of training, teaching requirements, learning content, and learning principles. It is an important basis for classroom teaching and testing. The quality of teaching materials directly affects the quality of Chinese teaching and plays a vital role in the process of students learning Chinese. At present, there is still a gap between the excellent textbook "Experience Chinese" promoted by Office of Chinese Language Council International and the actual needs of primary school students in Thailand. Office of Chinese Language Council International should assist the Ministry of Education and local publishing houses in Thailand to jointly develop Chinese-Thai culture and conform to the teaching rules, which is in line with the characteristics of Thai primary school students: localized, serialized, scientific, and three-dimensional textbooks. The preparation of teaching materials should pay attention to the accuracy of the language specification, the difficulty should be moderate, and the appropriate amount of interesting content such as music, painting and handwork. At the same time, we should also do a good job of supporting teachers' books, workbooks, activity books, supporting reading materials and multimedia software matching with the texts.

\section{Conclusion}


The Chinese language learning fever in Thailand has enabled more and more primary school students to join the Chinese learning team. Thai elementary school Chinese teaching has received extensive attention in the Chinese teaching community as a new educational undertaking. As we all know, primary school students' learning motivation, learning interest, learning needs and thinking ability are different from those of adults, and they are unique characteristics as teaching objects. From the perspective of language teaching, the success of Chinese teaching in primary school directly determines the attitudes and interests of these children in Chinese language learning in the future. As an educator, we should profoundly understand and understand the differences in the educational environment and teaching models of Chinese and Thai students in order to better carry out Chinese teaching. At the same time, we should also pay attention to and strengthen the study of Chinese language teaching for primary school students in Thailand, so that the Chinese language teaching in Thailand is developing better and better with the support of Office of Chinese Language Council International.

\section{References}

[1] Yu Guo. Second Language Acquisition Theory Bow Chinese Teaching Research [M]. Beijing: Guangming Press, 2010.

[2] Wu Weishan, Yan Huixian. Introduction to Intercultural Communication [M]. Beijing Commercial Press, 2010.

[3] Qiao Mengdie. Characteristics and Strategies of Teaching Chinese as a Foreign Language for Children[J] Journal of Jilin College of Education, 2012(09).

[4] Peng Xiaoshuai. How to Improve the Interest of Overseas Chinese Offspring in LearningChinese[J]. Journal of the Chinese Language Institute of Jinan University, 2001(1).

[5]Tang Yaner. Children's Language Learning Psychology [M]. Guangzhou: Jinan University Press, 2012.

[6] Huang Nanjin, Feng Xue, Qiu Yuhua, Wang Qian, Sun You, Zhao Yanqiu. Investigation and Research on the Teaching of Chinese as a Foreign Language in Central Thailand [J]. Journal of Liuzhou Vocational and Technical College, 2013, (04).

[7] Zhao Jinming. Teaching Environment and Chinese Textbooks [J] World Chinese Teaching, 2009(2) 